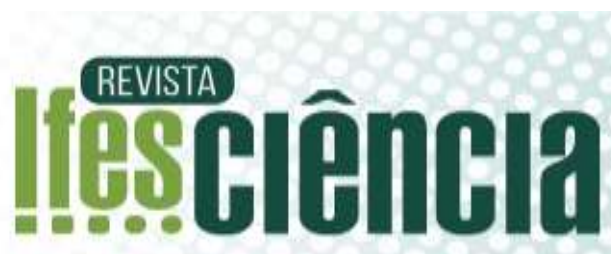

\section{O CARÁTER EQUALITÁRIO DAS COTAS ÉTNICO-RACIAIS}

\author{
THE EQUALITARIAN CHARACTER OF THE ETHNIC-RACIAL QUOTAS
}

\author{
João Vitor Ramos Guimarães \\ Instituto Federal do Espírito Santo. E-mail: joaovitoramosguimaraes@outlook.com
}

Artigo submetido em 05/03/2019, aceito em 15/06/2019 e publicado em 23/12/2019.

\begin{abstract}
Resumo: O presente artigo estabelece um paralelo entre os materiais bibliográficos referentes ao período escravocrata vivido no Brasil, bem como suas cicatrizes pulsantes até os dias atuais. Pretendese, por meio desse histórico legitimar as lutas do Movimento Negro para o rompimento do ciclo vicioso, no qual o negro mantém-se como a base do sistema hierárquico capitalista, permanecendo marginalizado pela, e na sociedade. Com base em pesquisa bibliográfica, pesquisa documental e no método materialista histórico-dialético, foi atribuído corpo à ideia de produzir um material científico que apresentasse questionamentos e viabilizasse um suporte para reflexões acerca das disparidades entre negros e brancos no Brasil, sobretudo na área educacional. Objetiva-se com isso, discutir a política de cotas étnico-raciais como um mecanismo de justiça social e de democratização do ensino, tendo por finalidade viabilizar o ingresso de pretos, pardos e indígenas no sistema federal de ensino médio e superior público, com o propósito de reparar a dívida histórica com o grupo que por tanto tempo teve seus direitos negados, e que anseia pela retirada completa de suas amarras.
\end{abstract}

Palavras-chave: Ações afirmativas; cotas étnico-raciais; educação; Movimento Negro; racismo.

\begin{abstract}
This article establishes a parallel between the bibliographic materials related to the slavery period lived in Brazil, as well as their pulsating scars up to the present day. Through this history, we intend to legitimize the struggles of the Black Movement to break the vicious cycle, in which black people remain the basis of the capitalist hierarchical system, remaining marginalized by, and in, society. Based on bibliographic research, documentary research and the historical-dialectical materialist method, the idea of producing a scientific material that would present questions and enable a support for reflections on the disparities between blacks and whites in Brazil, especially in the educational area. The objective is to discuss the policy of ethnic-racial quotas as a mechanism of social justice and democratization of education, with the purpose of making possible the entry of blacks, browns and indigenous people into the federal system of public high and higher education, with the purpose of repairing the historical debt with the group that for so long had its rights denied, and that longs for the complete removal of its tethers.
\end{abstract}

Keywords: affirmative actions; ethnic-racial quotas; education, Black Movement; racism.

\section{INTRODUÇÃO}

A trajetória do Brasil, assim como a de inúmeros outros países colonizados, é marcada pelo desejo do homem, especialmente branco europeu, de exercer o poder $^{1}$ sobre os demais, que, erroneamente foram (e são) subjugados inferiores. Na Ilha

\footnotetext{
${ }^{1}$ Termo bastante analisado na conversação entre os teóricos Michel Foucault e Gilles Deleuze,
} 
de Vera $\mathrm{Cruz}^{2}$, por exemplo, a herança do período escravocrata permanece sendo ostentada em diferentes esferas sociais, nas quais o quadro da desigualdade apenas sofreu alterações em sua moldura, pois a história nelas retratadas continua a mesma. Nelas, a marginalização e a exclusão da comunidade negra mantém-se: a Casa Grande moderna, por meio de uma releitura social, substitui navios negreiros por camburões polícias; senzalas por presídios; amas de leite por empregadas domésticas; cortiços por favelas; enfim, a readaptação de meios que garantam a perpetuação do destino secundarista da maior parte dos afro-brasileiros.

Diante desse quadro, e a partir das constantes reivindicações do Movimento Negro por oportunidades igualitárias, o governo desenvolveu as políticas de ação afirmativa, que contemplam diversas áreas da esfera social, na busca por mitigar as iniquidades raciais entre negros e brancos, através da distribuição igualitária de oportunidades para todos. "Foram importantes nesse processo os diversos eventos relacionados com a preparação para a III Conferência Mundial das Nações Unidas contra o Racismo, Xenofobia e Intolerância Correlata (realizada em Durban, em 2001)" (SILVA et al., 2018, p. 166). A política de cotas possibilita que os negros $^{3}$ desenvolvam seus potenciais que por tanto tempo foram negados e negligenciados. As cotas étnico-raciais se constituem em uma forma de combate às desigualdades entre negros e brancos construídas historicamente e perpetuadas até o presente. Nelas, a porcentagem de vagas em universidades e institutos federais destinadas aos pretos, pardos e indígenas, é determinada levando-se em conta o "(...)

denominada: Os intelectuais $e \quad o$ poder (FOUCAULT, 1989).

2 Primeiro nome dado pelos portugueses recém chegados à América ao Novo Mundo, hoje identificado como Brasil.

3 "Entendemos como negros o somatório das pessoas que se autodeclaram pretos e pardos, categorias utilizadas pelo IBGE e por muitas entidades do Movimento Negro" (SANTOS, 2015, p. 108). percentual mínimo correspondente ao da soma de pretos, pardos e indígenas no estado, de acordo com o último censo demográfico do Instituto Brasileiro de Geografia e Estatística (IBGE)" (BRASIL, 2012), tendo ainda que atender ao critério de carência socioeconômica e/ou ser aluno oriundo do ensino público.

Com a aprovação da Lei n. 12.711, o Ministério da Educação (MEC) adotou, em 29 de agosto de 2012 (BRASIL, 2012), a política pública de reserva de vagas destinada a alunos socialmente carentes e/ou pretos, pardos e indígenas (PPI), em todo o sistema federal de ensino médio e superior público. De acordo com Daflon et al. (2013, p. 313), "Entre as 70 universidades públicas que hoje adotam essas medidas, de um total de 96, são estaduais 44\% e federais, 56\%". Conforme a Pesquisa Nacional por Amostra de Domicílios (PNAD), do IBGE de 2018, "houve aumento no percentual de pessoas com 25 anos ou mais idade com ensino superior completo, passando de 15,3\% em 2016 para $15,7 \%$ em 2017. Entre os brancos, 22,9\% haviam concluído essa etapa, e na população preta e parda, 9,3\%".

Diante do descompasso entre o alto número de universidades públicas adeptas ao sistema de cotas e da disparidade entre negros e brancos no sistema federal de ensino superior brasileiro, este artigo pretende enfatizar, entre outros, os motivos pelos quais o negro ainda está, quando comparado ao branco, em pé de desigualdade. Bem como legitimar a criação das políticas de ação afirmativa, em especial as cotas étnico-raciais, como dispositivo de combate às desigualdades raciais. Além disso, reforçar para a sociedade brasileira, a importância dessa política pública como plataforma formadora de ambientes universitários heterogêneos, possibilitando um lugar de fala pluralizado, para que todos os grupos, sobretudo as minorias, possam expressar-se por si mesmo.

Frente a uma inquietação pessoal, que proporcionou deslocar-me do comportamento cotidiano para a esfera do humano-genérico (HELLER, 1989; MARX, 
2011), atribuí corpo à ideia de produzir um material científico que apresentasse questionamentos e viabilizasse um suporte para reflexões acerca das disparidades entre negros e brancos no Brasil, sobretudo na área educacional. A partir dessa perspectiva dialética, me apropriei do caráter informativo que a literatura exerce sobre a vida, para fortalecer por meio deste artigo, a importância da manutenção da política de cotas étnico-raciais nos institutos e universidades federais, enquanto se fizer necessário combater as iniquidades entre negros e brancos no país.

\section{PROCESSOS METODOLÓGICOS: MATERIAIS E MÉTODOS}

Este estudo se constitui em uma pesquisa bibliográfica e documental (LAVILLE; DIONE, 1999) que busca destacar algumas das situações de privação social, econômica, política e, sobretudo educacional, sofridas pelo negro desde o período escravocrata até os dias atuais. Para tanto foi utilizado como fonte para coleta de dados livros, artigos científicos e jornalísticos, músicas, Leis e dados estatísticos (IBGE e PNAD). Gil (2008, p. 50) enfatiza que dentre os benefícios da pesquisa bibliográfica, o maior deles consiste em proporcionar ao investigador a "cobertura de uma gama de fenômenos muito mais ampla do que aquela que poderia pesquisar diretamente".

Apoiando-se no método materialista histórico-dialético (MARX, 2011), referencial teórico de entendimento da realidade, buscou-se captar a política de cotas étnico-raciais na perspectiva de sua totalidade, isto é, relacionando um conjunto de fatores de ordem social, histórica, econômica, política e educacional que permitam entender o fenômeno em toda sua complexidade. Para o método marxista "importa descobrir as leis dos fenômenos de cuja investigação se ocupa; o que importa é captar, detalhadamente, as articulações dos problemas em estudo, analisar as evoluções, rastrear as conexões sobre os fenômenos que os envolvem" (PIRES,1997, p. 85-86).

Pensando nisso, o estudo foi dividido em três etapas. A primeira consistiu em um levantamento bibliográfico a partir de livros e artigos científicos mostrando a situação do africano e do afrodescendente no período escravocrata no Brasil. $\mathrm{Na}$ segunda etapa, pesquisa documental, baseou-se em artigos jornalísticos e Leis, tendo por objetivo observar situações de privação social, econômica, política e, sobretudo educacional que permanecem atingindo a população afro-brasileira nos dias atuais. $\mathrm{Na}$ terceira etapa, buscou-se, por meio de dados estatísticos (IBGE e PNAD) atentar para a situação do negro a partir da implementação das ações afirmativas, com enfoque na política de cotas étnico-raciais voltada para o plano educacional.

\subsection{REMINISCÊNCIAS DE UMA SOCIEDADE NARCISISTA}

No início do processo de colonização do Brasil, os lusitanos apropriaram-se dos conhecimentos dos nativos sobre o território, a agricultura e a produção de medicamentos naturais, como forma de enriquecimento; como mecanismo de adaptação aos fenômenos naturais do Novo Mundo; mas, sobretudo, como forma de manutenção do poder sobre os ameríndios, que serviram de mão de obra escrava para a realização de trabalhos forçados em prol do crescimento da colônia e dos proprietários dos meios sociais de produção. Após sistemáticas tentativas de fugas $\mathrm{da}$ comunidade indígena, por conhecerem as terras "como a palma das suas mãos", e dos interesses da Companhia de Jesus em catequizá-los recrutando mais seguidores para a doutrina cristã, fez-se necessário que os lusitanos optassem por uma mão de obra alternativa, no caso, a africana, apesar da escravização indígena continuar ocorrendo

O continente africano é considerado o berço da humanidade, mas nem por isso 
foi isento de sofrer com as represálias suscitadas pelo homem branco. Teve suas riquezas territoriais retiradas e exportadas para diversos continentes, assim como seu povo, que foi capturado nas terras onde viviam e trazidos à força para a América, no objetivo de servirem aos desejos dos seus opressores. Os africanos eram transportados em navios negreiros que apresentavam condições desumanas e brutais. Muitos morriam nas travessias, vítimas de doenças, de monstruosidades e, em alguns casos, jogados ao mar, presos por correntes. Isso ocorreu, por exemplo, no navio britânico Zong, sob capitânia do Luke Collingwood. Genocídios como esse eram sustentados por discursos de coisificação ${ }^{4}$ que desumanizam os negros, como foi o caso da declaração dada pelo juiz, Lord Mansfield, sobre o navio Zong, em que disse: "O que é essa afirmação de que seres humanos foram jogados ao mar? Este é um caso de bens móveis ou mercadorias. Os negros são bens e propriedades, é loucura acusar estes homens honrosos de assassinato" (RODRIGUES, 2013).

Os negros que sobreviveram a todas essas barbáries eram logo separados do seu grupo identitário e misturados com outros de tribos diversas, para que não pudessem se comunicar, muito menos articular uma forma para adquirir a liberdade. Tinham como principal serventia o trabalho braçal, eram vendidos e incessantemente expostos a castigos físicos e psicológicos severos, além de terem todos os seus direitos como indivíduos negados. No caso das mulheres, ainda eram abusadas sexualmente por inúmeros senhores de engenho, que consideravam-se proprietários dos seus corpos; e foi por meio dessa servidão que deu-se início ao processo de miscigenação no Brasil.

Após a abolição da escravatura, que por muito tempo foi postergada pela monarquia portuguesa por compor o sistema

\footnotetext{
${ }^{4}$ Processo no qual é retirado do homem seu caráter genérico, e com isso sua atividade livre, consciente, reflexiva, sua natureza inorgânica; transformando-o em uma mercadoria, uma coisa (MARX, 2011).
}

econômico do período, os negros tornaramse "livres"; no entanto, sem nenhuma política de reparação e integração. O negro foi disposto na sociedade, permanecendo vítima do racismo e dos estigmais sociais e, consequentemente, marginalizado e excluído. Guiados pela falsa sensação de liberdade, os afrodescendentes trocam as senzalas pelas regiões periféricas das metrópoles, estabelecendo o início do processo de favelização.

Discursos racistas alimentam a ideologia acerca da supremacia de uma raça $a^{5}$ sobre outra. De acordo com Munanga (2004, p. 8):

(...) a raça no imaginário do racista não é exclusivamente um grupo definido pelos traços físicos. A raça na cabeça dele é um grupo social com traços culturais, lingüísticos, religiosos, etc. que ele considera naturalmente inferiores ao grupo a qual ele pertence. De outro modo, o racismo é essa tendência que consiste em considerar que as características intelectuais e morais de um dado grupo, são conseqüências diretas de suas características físicas ou biológicas.

O período escravocrata é o maior exemplo disso, no qual o homem branco sentiu-se livre para reprimir toda e qualquer cultura subjugada inferior a sua, “(...) procuraram destruir, ou pelo menos castrar, tudo o que fosse expressão viril de cultura artística ou religiosa em desacordo com a moral católica e com as convenções europeias. Separaram a arte da vida" (FREYRE, 1987, p. 109).

Vale salientar que a comunidade negra era constituída por reis e rainhas,

\footnotetext{
5 “Alguns biólogos antirracistas chegaram até sugerir que o conceito de raça fosse banido dos dicionários e dos textos científicos. No entanto, o conceito persiste tanto no uso popular como em trabalhos e estudos produzidos na área das ciências sociais. Estes, embora concordem com as conclusões da atual Biologia Humana sobre a inexistência científica da raça e a inoperacionalidade do próprio conceito, eles justificam o uso do conceito como realidade social e política, considerando a raça como uma construção sociológica e uma categoria social de dominação e de exclusão" (MUNANGA, 2004, p. 6).
} 
possuíam suas religiões, seus cultos, seus costumes, suas artes, seus mitos e seus sistemas de cidade-Estado, e toda essa construção identitária foi demonizada e sufocada pela etnia branca dominante. "É que Narciso acha feio o que não é espelho" (CAETANO VELOSO, Sampa, 1992). Tal ocorrido, desencadeou o processo de negação do afrodescendente, que ao não se identificar nas manifestações culturais dos seus ancestrais, por essas estarem intrinsecamente associadas a uma leitura negativa feita pelo corpo social, aproximase da cultura do colonizador no intuito de ser melhor inserido na sociedade; deixando de compreender seu papel de construtor na sua própria história.

\subsection{HERANÇAS DO PERÍODO COLONIAL NO BRASIL DO SÉC. XXI}

Por ser o Brasil, um país com apenas 518 anos de narrativas registradas, é comumente esperado que sua população apresente um maior domínio sobre sua bibliografia, assim como de suas origens. Notadamente, o que ocorre é justamente o contrário, há um enorme afastamento do indivíduo da sua história, que por muitas vezes é confundida como misticismo ou, até mesmo, como um mero conteúdo a ser gravado e reproduzido em determinados contextos acadêmicos. A ausência da compreensão e sensibilidade por sua própria história, e do que determinado sujeito, bem como seu povo, representam numa leitura social, contribui para a propagação de preconceitos e familiaridade com a desigualdade. $\mathrm{Na}$ comunidade negra, "A falta de conhecimento sobre suas origens contribui para que os afrodescendentes tenham pouca autoestima, o que impede seu acesso pleno às oportunidades e mina sua capacidade de lutar por direitos" (NASCIMENTO, 2008, p. 14).

$\mathrm{O}$ esquecimento e a indiferença atribuída à trajetória de formação do povo brasileiro, implica na aceitação da hierarquia étnico-racial notoriamente enraizada nessa sociedade, bem como a naturalização do papel de submissão destinado aos negros, sem o questionamento do porquê ser disposto dessa maneira. O distanciamento da origem histórica, camufla inquietações acerca dos privilégios que o tom de pele branco exerce sobre os demais, neste caso, o "defeito de uma cor"6 e todos os estigmas trazidos por ela, em detrimento a outra mais prestigiada e mundialmente aceita.

Articular historicamente o passado não significa conhecê-lo "como ele de fato foi". Significa apropriar-se de uma reminiscência, tal como ela relampeja no momento de um perigo. Cabe ao materialismo histórico fixar uma imagem do passado, como ela se apresenta no momento do perigo, ao sujeito histórico, sem que ele tenha consciência disso. O perigo ameaça tanto a existência da tradição como os que a recebem. Para ambos, o perigo é o mesmo: entregar-se às classes dominantes, como seu instrumento (BENJAMIN, 1987, p. 224).

O processo de branqueamento $^{7}$ que ocorreu em concomitância com a abolição da escravatura, no qual imigrantes vieram para o Brasil em busca de trabalho, e os negros novamente foram anulados das oportunidades, apenas reforçou o quadro do eurocentrismo vigente no período, garantindo que fosse perpetuado até os tempos atuais. É importante o reconhecimento de que houve sim um avanço, e uma ocupação de grandes cargos por integrantes da comunidade negra no decorrer dos anos, mas, tratando-se de uma etnia que representa mais de $54 \%^{8}$ da

\footnotetext{
6 “'(...) defeito de cor, que não permitia que os pretos, pardos e mulatos exercessem qualquer cargo importante na religião, no governo ou na política" (GONÇALVES, 2006, p. 214).

7 "A política e a ideologia do branqueamento exerceram uma pressão psicológica muito forte sobre os africanos e seus descendentes. Foram, pela coação, forçados a alienar sua identidade transformando-se, cultural e fisicamente em brancos" (MUNANGA, 1999, p. 94).

${ }^{8}$ De acordo com a Pesquisa Nacional por Amostra de Domicílios (PNAD), do Instituto Brasileiro de Geografia e Estatística (IBGE) de 2015, dos
} 
população brasileira, essa ascensão é relativamente pequena.

Uma simples pergunta que nos ajuda a refletir é: quantas autoras e autores negros o leitor e a leitora, que cursaram a faculdade, leram ou tiveram acesso durante o período da graduação? Quantas professoras ou professores negros tiveram? Quantos jornalistas negros, de ambos os sexos, existem nas principais redações do país ou até mesmo nas mídias ditas alternativas? (RIBEIRO, 2017, p. 66).

Grande parte da população negra no Brasil, por uma questão histórica, sofre com o processo de segregação socioespacial ${ }^{9}$, passando a ocupar em sua maioria as bordas das cidades, enfrentando a baixa qualidade de vida, a ausência de escolas, de unidades públicas de saúde e, em muitos casos, a ausência de tratamento de água potável e esgoto. Nos bairros periféricos é comum a insuficiência de escolas, com isso os alunos precisam deslocar-se por conduções públicas até os colégios mais próximos, que às vezes ficam a quadras de distância, todavia, para que esse trajeto aconteça é preciso que os mesmos possuam uma renda capaz de garantir esse deslocamento, o que para muitos não é uma realidade cabível. As dificuldades são inúmeras e, novamente, aqueles que por elas se sobressaem, encerram uma luta e logo iniciam a seguinte:

Agora ela cresceu, quer muito estudar

Termina a escola, a apostila, ainda tem vestibular

E a boca seca, seca, nem um cuspe

Vai pagar a faculdade, porque preto e pobre não vai pra USP

Foi o que disse a professora que ensinava lá na escola

Que todos são iguais e que cota é esmola

autodeclarados negros, $8,86 \%$ são pretos, enquanto $45,06 \%$ se afirmam pardos.

9 A segregação socioespacial funciona como um espelho das desigualdades sociais, logo, reflete a divisão dos grupos socioeconômicos e/ou étnicos, dentro de um determinado espaço (NEGRI, 2008).
Cansada de esmolas e sem o dim da faculdade

Ela ainda acorda cedo e limpa três apê no centro da cidade

Experimenta nascer preto, pobre na comunidade

Cê vai ver como são diferentes as oportunidades

(BIA FERREIRA, Cota Não é Esmola, 2018).

Os jovens negros, após transpassarem inúmeros obstáculos acentuados pelo seu tom de pele, deparamse com as dificuldades de ingressar em uma universidade pública federal, além de serem constantemente desestimulados e subjugados pelo sistema elitista. Desde cedo são expostos a discursos meritocráticos ${ }^{10}$, que partem do princípio que todos possuem as mesmas oportunidades, isto é, o que diferencia o fracasso do sucesso é apenas o esforço, a dedicação e o intelecto, contudo, o dia a dia está a todo o momento retratando a verdade, a minoria ${ }^{11}$ “(...) torna-se tanto mais pobre quanto mais riqueza produz, quanto mais a sua produção aumenta em poder e extensão" (MARX, 2011, p.111), diferente dos privilegiados ${ }^{12}$, a quem a riqueza, as oportunidades, e o amparo do Estado lhes são atribuídos de geração a geração.

Reconhecer seus privilégios é reconhecer sua história e compreender que sua posição hierárquica, que suas vantagens e independência, foram construídos a partir da retirada dos direitos das minorias. De

10 “(...) a única diferença aceitável para uma sociedade neoliberal é a meritocrática. Quem teve a nota mais alta ganha vaga, aí ninguém discute. $\mathrm{O}$ problema é que uma meritocracia só seria justa se todos pudessem concorrer a partir de condições iguais ou parecidas" (CALLIGARIS, 1999).

11 Minoritários em termos de direitos, e não em número populacional (RIBEIRO, 2017).

$12 \mathrm{O}$ privilégio é um reflexo das assimetrias ocasionadas historicamente por questões raciais, de gênero, econômica, e/ou de classe, no qual determinado grupo social é mais privilegiado, com isso, detêm mais benefícios e vantagens do que outros. Logo, é um “(...) sistema de hierarquização social _ que consiste em gradações de prestígio por classe social (ocupação e renda), origem familiar, cor e educação formal" (GUIMARÃES, 1995, p. 35). 
acordo com pesquisa realizada no ano de 2019, com 2.086 pessoas das cinco regiões brasileiras, pela organização internacional Oxfam Brasil, em parceria com o Instituto Datafolha: $64 \%$ dos entrevistados concordam que "mulheres ganham menos por serem mulheres", $52 \%$ que "negros ganham menos pelo fato de serem negros" e $72 \%$ que a cor da pele influencia a decisão de contratação por empresas (O GLOBO, 2019), material esse que denuncia não só o racismo e o sexismo presente nas instituições brasileiras, como também evidencia os enfrentamentos, sobretudo, experienciados pela mulher negra, que tem sobre seu corpo atravessamentos de gênero e de raça. Tal fato implica na necessidade de combater discursos eurocentristas, racistas, machistas e meritocráticos, em prol de uma sociedade mais justa e realmente equitativa, na qual todos verdadeiramente tenham seu lugar de fala ${ }^{13}$ garantido.

\subsection{AÇÕES AFIRMATIVAS}

Após 130 anos de uma falsa abolição da escravatura, a comunidade negra permanece refém do racismo institucional, refletido nos mais diversos setores sociais. De acordo com os dados coletados pela PNAD, do IBGE de 2018, "houve aumento no percentual de pessoas com 25 anos ou mais idade com ensino superior completo, passando de 15,3\% em 2016 para 15,7\% em 2017. Entre os brancos, $22,9 \%$ haviam concluído essa etapa, e na população preta e parda, 9,3\%". Apesar do crescimento no percentual de pessoas com ensino superior completo, ainda existe uma diferença de $13,6 \%$ entre brancos e negros com graduação completa. Quanto maior o grau de escolarização, maior é a diferença entre brancos e negros no ambiente acadêmico.

Conforme o IBGE (2017): “A taxa de analfabetismo no país foi de 7,2\% em 2016 (o que correspondia a 11,8 milhões de

13 "Pensar lugar de fala seria romper com o silêncio instituído para quem foi subalternizado, um movimento no sentido de romper com a hierarquia" (RIBEIRO, 2017, p. 92). analfabetos) (...) Para pessoas pretas ou pardas, essa taxa $(9,9 \%)$ era mais que duas vezes a das brancas $(4,2 \%)$ ". Ainda segundo o IBGE (2017), "Em média, a população do país tinha 8,0 anos de estudo (...) As pessoas brancas mostraram-se mais escolarizadas $(9$ anos) em relação às pretas ou pardas $(7,1$ anos)". As informações coletadas nas pesquisas, descortinam e evidenciam o quadro da desigualdade racial presente no Brasil, no qual os números equivalem às consequências da disparidade entre brancos e negros no contex to educacional.

A sociedade do século XXI, mantém conservado o etnocentrismo herdado do período colonial, manifestado de maneira velada e estampada, indo de injúrias e olhares até um slogan que perpetua a ideia de que o Brasil é um país miscigenado, logo, "um país de todos". O mito da democracia racial $^{14}$, reforça, ao mesmo tempo que encobre, o racismo experienciado pelos afrodescendentes, objetivando enfraquecer as lutas pautadas pelo corpo social negro, que passam a ter suas denúncias analisadas como vitimismo. A partir das reivindicações do coletivo negro por oportunidades igualitárias, e para a restituição de humanidades negadas ${ }^{15}$, o Estado desenvolve uma política pública, a política de ações afirmativas, que objetiva retificar as desigualdades raciais presentes na sociedade em diferentes esferas sociais.

Desde os anos de 1940 o corpo social negro reivindicava ao Estado Brasileiro ações que democratizassem o acesso e permanência dos afro-brasileiros em diferentes esferas sociais, sobretudo no âmbito educacional. Em 1946, ano em que

\footnotetext{
14 “(...) a partir das décadas de 1940 e 1950, novos dados sobre as desigualdades entre brancos e negros e sobre o racismo foram desvelados e a concepção de democracia racial foi questionada, passando a ser considerada um mito. As ideias de relações raciais harmónicas foram desnudadas como servindo à hegemonia branca no Brasil” (SILVA et al., 2018, p. 177).

15 Termo utilizado pela professora da Universidade Federal do Rio de Janeiro, Giovana Xavier, em seu artigo denominado: Feminismo: direitos autorais de uma prática linda e preta (XAVIER, 2017).
} 
aconteceu a Assembleia Nacional Constituinte para a elaboração de uma nova constituição, foi apresentado um "Manifesto à Nação Brasileira”, organizado pela Convenção Nacional do Negro Brasileiro, com a finalidade de requerer políticas públicas que remediassem as iniquidades entre negros e brancos no Brasil. De acordo com Silva et al. (2018, p. 164):

A ditadura militar de 1964 impôs limites aos movimentos sociais negros, mas a análise sobre as desigualdades raciais no Brasil ganhou novos contornos a partir do final da década de 1970, com reorganização dos movimentos negros, a inclusão de quesitos sobre raça na PNAD de 1976 e o retomar de pesquisas sobre desigualdades raciais.

A participação do Movimento Negro e de outros movimentos sociais, foi de suma importância para educar o povo brasileiro, no sentido de informar, de problematizar e de descortinar, o que para os negros já era explícito: o racismo institucional e estrutural, e a liquidez na forma como ele se manifesta. Nos anos finais do século XX, os assuntos relacionados às políticas de ação afirmativa foram implementadas na pauta governamental, passando a ser demandados com maior fervor pelo corpo social negro que, embasou suas reivindicações em fundamentos científicos que não comprovaram apenas a necessidade de se reverter as desigualdades entre negros $\mathrm{e}$ brancos no Brasil, mas também apresentaram o caráter reparatório que se faz presente nessa política pública.

Ainda sobre o fim dos anos de 1980, ocorreu a aprovação da Constituição da República Federativa do Brasil de 1988, que representa uns dos maiores momentos de democratização do Estado Brasileiro, e dela decorre a legitimação das ações afirmativas. No plano educacional, as cotas étnicoraciais conquistaram sua constitucionalidade em 2012, com a aprovação da Lei n. 12.711, que determina um percentual mínimo de vagas nas instituições federais, correspondente à soma dos pretos, pardos e indígenas no estado, conforme o último censo demográfico do IBGE (BRASIL, 2012). "Até a aprovação da lei federal antes citada, a ação afirmativa se disseminou pelo país de forma heterogênea, a partir de iniciativas locais, como leis estaduais e deliberações de conselhos universitários" (DAFLON et al., 2013, p. 305), como por exemplo a iniciativa do governo do Rio de Janeiro, em 2001, de estabelecer reserva de no mínimo $40 \%$ de vagas nas universidades estaduais do Rio. O mesmo ocorreu em 2002 na Universidade Estadual da Bahia (UNEB). A primeira universidade federal a adotar reserva de vagas para alunos negros foi a Universidade de Brasília (UnB), em 2003, destinando $20 \%$ das vagas do processo seletivo para os afrodescendentes.

Ações afirmativas são políticas públicas feitas pelo governo ou pela iniciativa privada com o objetivo de corrigir desigualdades raciais presentes na sociedade, acumuladas ao longo de anos. Uma ação afirmativa busca oferecer igualdade de oportunidades a todos. As ações afirmativas podem ser de três tipos: com o objetivo de reverter a representação negativa dos negros; para promover igualdade de oportunidades; e para combater o preconceito e o racismo (BRASIL, 2015).

Incontáveis são as pessoas que buscam desvalidar, o que por meio de anos de luta foi conquistado pelos negros. Usam de discursos que colocam os afrodescendentes como precursores do racismo contra si próprios, acusando-os de autoflagelação ${ }^{16}$, mas, sobretudo, por acreditarem que o racismo no Brasil é uma farsa e que a dívida histórica para com os negros ficou no passado. Afirmam a inutilidade de uma política pública com esse cunho.

\footnotetext{
16 Nesse contexto, de acordo com Du Bois (1961), conforme citado por Santos (2015, p. 116) "Esse dualismo, enquanto dicotomia cultural, implica um conflito psicológico para os negros, que dilaceram a si próprios como resultado da internalização da imagem do outro, simultaneamente rejeitado e desejado, construído pelo discurso hegemônico branco dominante".
} 
Em associação com o diagnóstico de que o problema central é de natureza racial, alguns setores da sociedade entenderam ainda que, além de mitigar a sub-representação de não brancos nas classes média e alta, as ações afirmativas devessem ainda desempenhar um papel simbólico de valorização do negro (DAFLON et al., 2013, p. 324).

Entretanto, é de suma importância reforçar a concepção de que "Uma ação afirmativa não deve ser vista como um benefício, ou algo injusto. Pelo contrário, a ação afirmativa só se faz necessária quando percebemos um histórico de injustiças e direitos que não foram assegurados" (BRASIL, 2015). Direitos historicamente negados ao corpo social negro, que foram coisificados e subjugados inferiores por um "defeito de cor" durante três séculos, sendo impedidos de ocuparem determinados ambientes e posições sociais.

(...) as opressões estruturais impedem que indivíduos de certos grupos tenham direito à fala, à humanidade. $\mathrm{O}$ fato de uma pessoa ser negra não significa que ela saberá refletir crítica e filosoficamente sobre as consequências do racismo. Inclusive, ela até poderá dizer que nunca sentiu racismo, que sua vivência não comporta ou que ela nunca passou por isso. E sabemos quanto alguns grupos adoram fazer o uso dessas pessoas. Mas o fato dessa pessoa dizer que não sentiu racismo, não faz com que, por conta de sua localização social, ela não tenha tido menos oportunidades e direitos (RIBEIRO, 2017, p. 70).

Independente do locus social ${ }^{17}$ que o negro ocupa na sociedade, ele não estará isento do racismo estrutural que o persegue desde os navios negreiros, dos olhares desconfiados, dos julgamentos e da descrença na qualidade do trabalho

\footnotetext{
17 Para entender lugar social, de acordo com Collins (1997), conforme citado por Ribeiro (2017, p. 63), "Seria preciso entender as categorias de raça, gênero, classe e sexualidade como elementos da estrutura social que emergem como dispositivos fundamentais que favorecem as desigualdades e criam grupos (...)".
}

intelectual prestado pelo mesmo. O lugar do negro está tão imposto e naturalizado pela sociedade, que não se questiona a ausência dos afrodescendentes em universidades, nas mídias e em lugares públicos de destaque. É importante ressaltar que as ações afirmativas, especialmente as cotas étnicoraciais, auxiliam na restauração dessas identidades políticas depreciadas e, também, na distribuição equitativa das oportunidades, viabilizando a reorganização social no que se refere aos cargos mais valorizados socialmente, consequentemente, colaborando para a desconstrução do olhar estereotipado da população brasileira a respeito dos afrodescendentes.

\section{RESULTADOS E DISCUSSÃO}

Com base na pesquisa bibliográfica e documental foi possível compreender as cotas étnico-raciais desenvolvidas para a área da educação e abarcadas pelas políticas de ação afirmativa, como uma demanda apresentada a público pelo Movimento Negro, que denunciou o quadro eurocentrista das universidades brasileiras, no qual a população negra era ínfima, tendo como historicamente seu direito à educação negado. A ausência dos afrodescendentes nas instituições de ensino podem ser explicada de diversas formas, por exemplo: muitos precisam trabalhar para contribuir com a renda familiar ou são o próprio provedor da fonte de renda da casa; grande parte não possui nenhuma forma de preparação para os exames de vestibulares, tornando a concorrência ainda mais desleal; ausência de políticas públicas que garantam a permanência desses sujeitos após o ingresso nas instituições públicas; além das universidades, como instituições sociais, serem reprodutoras do racismo existente na sociedade, inibindo o desejo do jovem de adentrar em um ambiente opressor, que a todo momento o mostrará que "ali não é o seu lugar".

Por ser uma ferramenta de estímulo à equidade, o sistema de cotas étnico- 
raciais, destina às minorias um percentual mínimo de vagas nas instituições federais, correspondente à soma dos pretos, pardos e indígenas no estado, conforme o último censo demográfico do IBGE (BRASIL, 2012), atendendo também, ao critério de carência socioeconômica e/ou aluno proveniente do ensino público; aquilombando, assim, esses ambientes e promovendo uma mudança no quadro social brasileiro. Com sua contribuição, os negros passaram a ter a oportunidade de apropriarse dos lugares e empregos de destaque, antes por eles não alcançados, e "Os motivos desse 'não alcançar' muitas vezes não são inerentes ao sistema de ensino, mas a uma série de determinantes sociais e econômicas que reforçam as condições de desfavorecimento com que os jovens se defrontam cotidianamente" (BRASIL, 2007, p. 27).

Acredita-se com essa política reparatória, que através do acesso à educação, os grupos étnicos-raciais desfavorecidos historicamente possam vir a emancipar-se do sistema opressor, reconstruindo suas identidades políticas. Essa reconstrução da humanidade diz respeito a um conjunto de mudanças, como por exemplo: a) por meio da educação, o indivíduo toma consciência de sua condição histórica, e luta pelo fim do ciclo vicioso de subalternização; b) possibilitar a uma família que por gerações não teve acesso ao ensino superior, uma oportunidade igualitária de ingressar em uma instituição pública; c) através das cotas étnicos-raciais uma maior quantidade de negros tem a oportunidade de se formar assistentes sociais, advogados, pesquisadores, psicólogos, professores, etc, servindo de espelho para a sua comunidade; d) por meio de uma formação especializada, os afrobrasileiros podem alcançar melhores colocações no mercado de trabalho; e) através da pluralidade étnico-racial dos pesquisadores, é possível se obter diferentes perspectivas sobre um mesmo objeto; f) a humanização promove a ressignificação do lugar do negro na sociedade, bem como a desconstrução do olhar negativo, repleto de estereótipos inferiores sobre os afrodescendentes.

O retroativo histórico é uma dívida estabelecida após 300 anos de escravidão, nos quais os negros eram negociados como mercadorias, sendo mantidos presos em senzalas, amarrados por correntes, obrigados a executarem trabalhos forçados com nenhuma remuneração ou direito garantidos, além de serem constantemente humilhados e sofrerem com as terríveis torturas desencadeadas pelos brancos; e, mesmo assim, após todo esse sofrimento, terem sido libertos da escravidão formal, sem nenhuma política de inclusão ou reparação, para o retrocesso produzido no seu povo.

Até os tempos atuais a comunidade afrodescendente vem sofrendo com os olhares construídos sobre uma égide negativa, repletos de estereótipos inferiores que acabaram sendo naturalizados. As cotas antirracismo surgem justamente para ressignificar o lugar do negro na sociedade, provendo meios para que esse grupo ocupe as universidades e, consequentemente, alcancem melhores colocações no mercado de trabalho. "Melhorar o índice de desenvolvimento humano de grupos vulneráveis deveria ser entendido como melhorar o índice de desenvolvimento humano de uma cidade, de um país" (RIBEIRO, 2017, p. 43). No entanto, o grupo dominante sente-se fragilizado e incomodado com a ascensão e a busca pelo lugar de fala de um grupo que por tanto tempo foi silenciado, desenvolvendo meios para desvalidar as políticas públicas alcançadas pela minoria. Esses meios estão presentes em alguns argumentos contrários às costas antirracismo, como por exemplo: a grande dificuldade para se definir quem é negro no Estado Brasileiro, já que o país tem o povo historicamente miscigenado, ponto esse que também é utilizado para a defesa de que não existe racismo no Brasil; as cotas sociais já contemplaria a comunidade negra, em sua maioria desprovida economicamente; as cotas 
étnico-raciais privilegiam uma raça em detrimento a outra, podendo ocasionar conflitos raciais; as cotas PPI são um mecanismo de reafirmação do racismo contra o negro; não ocorre mérito acadêmico nesse processo seletivo.

É percebido nas entrelinhas desses discursos, o racismo enraizado e naturalizado por grande parte da população brasileira, que se articula de forma consciente ou inconsciente, para manter as relações de subalternização de determinados grupos étnicos. Essa é uma das facetas do racismo, naturalizar as hierarquizações sociais fundamentado nas diferenças raciais, impondo aos seres humanos, a partir das suas características biológicas, seu papel nas relações de dominação.

De que lugar é esse do qual se fala, quando se produz a ideia de que as cotas raciais são um mecanismo de reafirmação do racismo contra o negro? De que lugar é esse do qual se fala, quando se reivindica as cotas raciais por ter um tataravô, uma bisavó, ou até mesmo um pai/mãe negro, sendo branco? De que lugar é esse do qual se fala, quando se acredita que as oportunidades para brancos e negros no Brasil são as mesmas? De um espaço construído no qual se acredita que a voz do colonizador é a universal, de um espaço que almeja a manutenção de privilégios e propagação de uma hierarquia já dominante. O que se nota não é somente uma enorme falta de informação e real conhecimento sobre a estrutura das cotas por muitos, mas sim o racismo velado do grupo hegemônico branco, pois "Falar de racismo (...) é visto geralmente como algo chato, 'mimimi' ou outras formas de deslegitimação. A tomada de consciência sobre o que significa desestabilizar a norma hegemônica ${ }^{18}$ é vista como inapropriada ou agressiva porque aí se está confrontando o poder" (RIBEIRO, 2017, p. 81).

\footnotetext{
18 "A imposição do modelo europeu como universal, por meios violentos e não violentos de dominação" (NASCIMENTO, 2008, p. 52).
}

Para a descolonização do pensamento $^{19}$, bem como o rompimento da ideia de que uma cota, no caso a socioeconômica, anularia a necessidade da étnico-racial, é preciso analisar as questões sociais em uma perspectiva mais ampla, questionando todos os padrões preestabelecidos que determinam as variantes experienciadas pelas minorias, que sofrem constantemente com as desigualdades provocadas pela iniquidade entre negros e brancos. Analisar as cotas étnico-raciais como um mecanismo de justiça social é compreender a trajetória histórica da comunidade negra e, com isso, refletir a respeito da importância dessa política pública para a luta contra a desigualdade racial, bem como para os enfrentamentos antirracistas. $\mathrm{O}$ polímata Rui Barbosa, no seu histórico discurso "Oração aos Moços", falou com clareza sobre a igualdade:

A regra da igualdade não consiste senão em quinhoar desigualmente aos desiguais, na medida em que se desigualam. Nesta desigualdade social, proporcionada à desigualdade natural, é que se acha a verdadeira lei da igualdade. O mais são desvarios da inveja, do orgulho, ou da loucura. Tratar com desigualdade a iguais, ou a desiguais com igualdade, seria desigualdade flagrante, e não igualdade real (BARBOSA, 2003, p. 19).

As cotas étnico-raciais são uma política de combate a homogeneidade branca da conjuntura universitária brasileira, por conseguinte, destina-se a denegrir ${ }^{20}$ os

19 “o resgate de sua cultura, do seu passado histórico negado e falsificado, da consciência de sua participação positiva na construção do Brasil, da cor de sua pele inferiorizada, etc... Ou seja, a recuperação de sua negritude, na sua complexidade biológica, cultural e ontológica" (MUNANGA, 1999, p. 101).

20 Termo bastante utilizado no sentido figurado, para referir-se a desonra, a difamação, a injúria etc, de algo/alguém, todavia, também representa a ação de tornar algo negro, de enegrecer um ambiente. Desse modo, torna-se evidente como o dualismo presente na língua brasileira reflete o racismo existente na 
ambientes acadêmicos, visando o embate antirracista. $\mathrm{O}$ processo seletivo para o estudante que opta pelo uso das cotas raciais no vestibular universitário é semelhante ao do aluno de ampla concorrência, ou de outras ações afirmativas. O objetivo da divisão em categorias sociais é para que os desiguais sejam tratados de acordo com a sua desigualdade, concorrendo igualmente entre si. Todavia, existe uma grande quantidade de estudantes brancos, que pela falta de conhecimentos fenótipos sobre o que é ser pardo, ou pela afro-conveniência, utilizam das cotas destinadas aos pretos, pardos e indígenas, para ingressarem de forma ilegítima nas instituições de ensino, usurpando os lugares das pessoas para qual essa política pública foi destinada. "Assim é o racismo brasileiro. Sem cara, travestido em roupas ilustradas, universalista, tratando-se a si mesmo como anti-racismo e negando como antinacional a presença integral do afro-brasileiro ou do índiobrasileiro" (GUIMARÃES, 1995, p. 42).

De acordo com a Revista Fórum (2017b, grifo nosso), “Já são dezenas de pessoas brancas que, de forma fraudulenta, se autodeclararam negras para ingressar no curso de Medicina da $U F M G^{21}$, um dos melhores do país, enquanto negros ficam de fora", a Fórum (2017a) ainda afirma que, "A partir de denúncias de estudantes negros, uma comissão da Universidade Federal do Rio Grande do Sul constatou que ao menos 239 estudantes brancos fraudaram o sistema de cotas raciais". A não punição dos inúmeros alunos fraudulentos das universidades federais, provoca a sensação de impunidade e injustiça para a comunidade negra, além da ação afirmativa passar a ter seu caráter dubitável e analisado no viés de uma falsa política de inclusão e incentivo a igualdade racial. Todavia, "apesar de problemas registrados em algumas universidades, pode-se dizer que o critério da autodeclaração conjugado com algum tipo de controle foi positivo" (SILVA et al., 2018, p. 170).

Apesar das inúmeras fraudes, as políticas de cotas étnico-raciais permanecem cumprindo seu papel na propagação da equidade, aumentando a chance de a população negra conquistar um diploma de graduação. De acordo com a Agência Brasil (2018):
A chance de ter um diploma de graduação aumentou quase quatro vezes para a população negra nas últimas décadas no Brasil. Depois de mais de 15 anos desde as primeiras experiências de ações afirmativas no ensino superior, o percentual de pretos e pardos que concluíram a graduação cresceu de 2,2\%, em 2000, para 9,3\% em 2017.

Além disso, "Dados da UnB mostram que (...) No acumulado de 2004 a 2018, ingressaram na universidade 7.648 negros pelo sistema de cotas raciais" (AGÊNCIA BRASIL, 2018). Tendo isso em vista, é correto afirmar que as denúncias não devem afetar o sistema de cotas PPI, mas sim contribuir para ajustes que garantam a continuidade no crescimento da quantidade de negros em ambientes acadêmicos, para quem a política pública foi desenvolvida.

Para que as cotas étnico-raciais cumpram seu papel antirracista na sociedade é preciso que a comunidade acadêmica, juntamente à população, reconheça a árdua trajetória histórica da comunidade negra, em um país extremamente racista como o Brasil, que desde o início da escravidão vem retirando vidas e oportunidades dos africanos e afrodescendentes. Cabe também, o reconhecimento de que as cotas raciais são uma conquista do movimento negro para os negros e que, portanto, essas minorias precisam ser contempladas.

sociedade, reforçando a associação do negro a imagem negativa.

${ }^{21}$ Universidade Federal de Minas Gerais. 


\section{CONCLUSÕES}

Os recortes históricos evidenciam a trajetória vivida pelo africano escravizado e as cicatrizes decorrentes dessa dominação. $\mathrm{E}$, por conseguinte, reconhecem as desigualdades de condições materiais e de oportunidades entre negros e brancos na sociedade brasileira, sobretudo, na área educacional.

Como forma de combate às dicotomias raciais presentes na sociedade brasileira, ocorre o surgimento das ações afirmativas, uma ferramenta social corretiva, conquistada pelo Movimento Negro, que objetiva proporcionar melhores condições de vida, acesso a bens culturais e igualdade social para os afrodescendentes. As cotas étnico-raciais são direcionadas para os grupos historicamente apartados dos direitos à cidadania, quiçá à educação emancipatória. Logo, as cotas raciais são voltadas para as questões educacionais, concedendo para as minorias raciais a oportunidade de (re)criar, por meio da educação, sua identidade político-social.

O modelo de cotas específicas fundamenta-se na compreensão que o racismo gera uma condição de desigualdade que é estrutural e estruturante da sociedade. Uma mulher ou homem negra/o deve ter direito ao programa de ação afirmativa não em função de sua condição econômica, mas por conta da discriminação racial que lhe é imputada e também como forma reparatória, independente de classe social (SILVA et al., 2018, p. 169).

Existe uma maior aceitabilidade da sociedade brasileira a respeito das cotas sociais em detrimento das étnico-raciais, com isso, diversos setores institucionais declaram-se contrários a existência dessa política, duvidosos enquanto o seu caráter igualitário e sustentam com segurança que as cotas sociais já contemplaria a comunidade negra, em sua maioria desprovida economicamente. Contudo, ao contrário do que postulam aqueles que defendem políticas estritamente sociais, essas não são, por si só, um mecanismo eficaz de inclusão de grupos étnico-raciais discriminados (DAFLON et al., 2013). O sistema socioeconômico não é a melhor forma de mitigar as assimetrias existentes entre brancos e negros em razão de ser limitado para englobar o racismo sofrida pela comunidade afro-brasileira.

Diante disso, ressalta-se a importância das ações afirmativas, sobretudo, das cotas étnico-raciais, como política pública de caráter igualitário e antirracista. Empregada como instrumento de justiça social e de combate às iniquidades raciais, as cotas viabilizam a heterogeneidade dos ambientes universitários, através do ingresso de pretos, pardos e indígenas, proporcionando-os a possibilidade de trilharem um caminho de protagonismo.

\section{REFERÊNCIAS}

BARBOSA, Rui. Oração aos Moços. Martin Claret: São Paulo, 2003.

BENJAMIN, Walter. "Sobre um conceito de história", In: Magia e técnica, arte e política: ensaios sobre literatura e história da cultura.Trad. Sergio Paulo Rouanet. 3 ed. São Paulo: Brasiliense, 1987, p.222-232.

IBGE - INSTITUTO BRASILEIRO DE
GEOGRAFIA E ESTATÍSTICA.
Analfabetismo cai em 2017, mas segue
acima da meta para 2015. 2018.
Disponível
<https://agenciadenoticias.ibge.gov.br/agen
cia-noticias/2012-agencia-de-
noticias/noticias/21255-analfabetismo-cai-
em-2017-mas-segue-acima-da-meta-para-
2015>. Acesso em: 18 fev. 2019.

Cor ou raça. 2015. Disponível em: $<$ https://educa.ibge.gov.br/jovens/conhecao-brasil/populacao/18319-cor-ouraca.html>. Acesso em: 04 fev. 2019.

PNAD Contínua 2016: $51 \%$ da população com 25 anos ou mais do Brasil possuíam apenas o ensino fundamental completo. 2017. Disponível em: 
$<$ https://agenciadenoticias.ibge.gov.br/agen cia-sala-de-imprensa/2013-agencia-denoticias/releases/18992-pnad-continua2016-51-da-populacao-com-25-anos-oumais-do-brasil-possuiam-apenas-o-ensinofundamental-completo>. Acesso em: $04 \mathrm{fev}$. 2019.

BRASIL. Ministério da Educação. Ensino Superior: entenda as cotas para quem estudou todo o ensino médio em escolas públicas. 2012. Disponível em: $<$ http://portal.mec.gov.br/cotas/perguntasfrequentes.html>. Acesso em: 08 mai. 2019.

Ministério da Educação. Secretaria de Educação Profissional e Tecnológica. Educação Profissional Técnica de Nível Médio Integrado ao Ensino Médio. Documento Base. Brasília, 2007.

Ministério dos Direitos Humanos. Secretaria Nacional de Políticas de Promoção da Igualdade Racial. O que são Ações Afirmativas. 2015. Disponível em: <http://www.seppir.gov.br/assuntos/o-quesao-acoes-afirmativas/o-que-e>. Acesso em: 22 dez. 2018.

CALLIGARIS, Contardo. Uma proposta para o Brasil não ser um clube. Folha de S.Paulo - ilustrada, 26 ago. 1999. Disponível em: <https://www1.folha.uol.com.br/fsp/ilustrad /fq26089925.htm>. Acesso em: 20 abr. 2019.

O GLOBO. Cresce percepção sobre discriminação de mulheres e negros no mercado de trabalho. 08 abr. 2019. Disponível em: <https://oglobo.globo.com/economia/cresce -percepcao-sobre-discriminacao-demulheres-negros-no-mercado-de-trabalho23576180>. Acesso em: 18 abr. 2019.

DAFLON, Verônica T. FERES JÚNIOR, João. CAMPOS, Luiz A. Ações Afirmativas Raciais no Ensino Superior Público Brasileiro: Um Panorama Analítico. Cadernos de Pesquisa, v.4, n.148, p.302-327. 2013. Disponível em: <http://www.scielo.br/pdf/cp/v43n148/15.p df $>$. Acesso em: 17 fev. 2019.
DU BOIS, W. E. B. (1961). The Soul of Black Folk. Greenwich, Conn: Fawcett Publications.

FERREIRA, Bia. Cota Não é Esmola. Estúdio Showlivre, 2018. Disponível em: <https://www.youtube.com/watch?v=QcQIa oHajoM>. Acesso em: 01 nov. 2018.

FREYRE, Gilberto. Casa-grande e senzala: formação da família brasileira sob o regime da economia patriarcal. $25^{\mathrm{a}} \mathrm{ed}$. Rio de Janeiro: José Olympio, 1987.

FOUCAULT, Michel. Os intelectuais e o poder: conversa entre Michel Foucault e Gilles Deleuze. FOUCAULT, Michel. Microfísica do poder. Organização e Tradução de Roberto Machado. Rio de Janeiro: Graal, 1989, 69-78. Disponível em: <https://edisciplinas.usp.br/pluginfile. $\mathrm{php} / 81012 / \mathrm{mod}$ _resource/content $/ 1 /$ Texto $\%$ $2016 \% 200$ s $\% 20$ intelectuais $\% 20 \mathrm{e} \% 20 \mathrm{o} \% 20$ poder.pdf>. Acesso em: 16 fev. 2019.

GIL, Antônio Carlos. Métodos e técnicas de pesquisa social. São Paulo: Atlas, 2008.

GONÇALVES, Ana Maria. Um defeito de cor. Rio de Janeiro: Record, 2006. Disponível em: <https://escrevivencia.files. wordpress.com/2014/03/um-defeito-decor.pdf> Acesso em: 02 nov. 2018.

GUIMARÃES, Antônio S. A. Racismo e antirracismo no Brasil. Novos Estudos CEBRAP , n.43, p.26-44. 1995. Disponível em: <https://edisciplinas.usp.br/pluginfile. php/4116181/mod_resource/content/0/A.\%2 0S.\%20Guimar\%C3\%A3es\%20-\%20

Racismo\%20e\%20anti-racismo\%20no\%20 Brasil.pdf>. Acesso em: 15 fev. 2019.

HELLER, Agnes. "Estrutura da vida cotidiana", In: O cotidiano e a história. São Paulo: Paz e Terra, 1989, p. 17-41.

LAVILLE, Christian; DIONNE, Jean. A construção do saber: Manual de metodologia da pesquisa em ciências humanas. Trad. Heloisa Monteiro e Francisco Settineri. Porto Alegre: Artes Médicas Sul, 1999. 
LONGO, Ivan. Fraude: Comissão da UFRGS aponta que 239 cotistas raciais não são negros nem pardos. Revista Fórum, 08 dez. 2017a. Disponível em: <https://www. revistaforum.com.br/fraude-comissao-daufrgs-aponta-que-239-cotistas-raciais-naosao-negros-nem-pardos/>. Acesso em: 06 fev. 2019.

LONGO, Ivan. No curso de Medicina da UFMG, brancos usam cotas para negros e tomam vagas de quem precisa. Revista Fórum, 24 set. 2017b. Disponível em: $<$ https://www.revistaforum.com.br/nocurso-de-medicina-da-ufmg-brancos-usamcotas-para-negros-e-tomam-vagas-de-quemprecisa/>. Acesso em: 06 fev. 2019.

MARX, Karl. Manuscritos econômicofilosóficos. São Paulo: Martin Claret, 2011.

MUNANGA, Kabengele. Rediscutindo a mestiçagem no Brasil: Identidade nacional versus identidade negra. Petrópolis: Vozes, 1999. Disponível em: <file:///C:/Users /JOOVIT 1/AppData/Local/Temp/docslide. com.br\%20rediscutindo-a-mesticagem-nobrasilkabengele-munanga.pdf $>$. Acesso em: 12 de fev. 2019.

Uma abordagem conceitual das noções de raça, racismo, identidade e etnia. Programa de Educação sobre o negro na sociedade brasileira, 2004. Disponível em:<https://www.geledes.org.br/wp-content /uploads/2014/04/Uma-abordagemconceitual-das-nocoes-de-raca-racismodentidade-e-etnia.pdf $>$. Acesso em: 22 abr. 2019.

NASCIMENTO, Elisa Larkin. A matriz africana no mundo. São Paulo: Selo Negro, 2008. Disponível em: <https://afrocentricidade.files.wordpress.co m/2016/04/a-matriz-africana-no-mundocolec3a7c3a3o-sankofa.pdf>. Acesso em: 03 nov. 2018.

NEGRI, Silvio M. Segregação SócioEspacial: Alguns Conceitos e Análises. COLETÂNEAS DO NOSSO TEMPO, Rondonópolis - MT, v. VII, n.8, p.129-153.
2008. Disponível em: <file:///C:/Users/ JOOVIT 1/AppData/Local/Temp/108-991-PB-1.pdf>. Acesso em: 18 fev. 2019.

PIRES, Marília Freitas de Campos. O materialismo histórico-dialético e a educação. Interface-comunicação, saúde, educação, 1997, 1: 83-94. Disponível em:< http://www.scielo.br/pdf/icse/v1n1/06.pdf>. Acesso em: 26 set. 2019.

RIBEIRO, Djamila. O que é: lugar de fala?. Belo Horizonte (MG): Letramento, 2017.

RODRIGUES, Dom. A chacina Zong: escravos jogados ao mar para os donos receberem o seguro. Kid Bentinho: História para curiosos, 16 mar. 2013. Disponível em: $<$ http://www.kidbentinho.com/2013/03/achacina-zong-escravos-jogados-aomar.html>. Acesso em: 01 nov. 2018.

SANTOS, S. P. Os "intrusos" e os "outros" oxigenando a universidade: por uma relação articulada entre raças e classe nas ações afirmativas. Espírito Santo (ES): Revista Simbiótica, vol. 2, n. 1, p.106-126. 2015. Disponível em: <http://periodicos.ufes .br/simbiotica/article/view/10329/7269>.

Acesso em: 20 nov. 2018.

SILVA, Paulo V. B. da. MARÇAL, José A. TRIGO, Rosa A. E. "Políticas de ações afirmativas no Brasil: Educação e Políticas Públicas". In: Roteiros temáticos da diáspora: caminhos para o enfrentamento ao racismo no Brasil [recurso eletrônico] /Andrea Maila Voss Kominek; Ana Crhistina Vanali (Orgs.) -- Porto Alegre, RS: Editora Fi, 2018, p. 159 - 188. Disponível em: <https://www.editorafi. org/396latitudes>. Acesso em: 26 set. 2019.

VELOSO, Caetano. Sampa. Rio de Janeiro: CBD Phonogram, 1992. Disponível em: < https://www.youtube.com/watch?v=qeDqX LkXvr4 >. Acesso em: 14 dez. 2018.

XAVIER, Giovana. Feminismo: direitos autorais de uma prática linda e preta. Folha de S.Paulo, 19 jul. 2017. Disponível em: <https://goo.gl/JVA9FJ>. Acesso em: 15 dez. 2018. 